\section{Shade and Photoperiod Influence Caryopteris incana Used as Cut Flowers}

\author{
Allan M. Armitage ${ }^{1}$ and Ki-Cheol Son ${ }^{2}$ \\ Department of Horticulture, University of Georgia, Athens, GA 30602
}

Additional index words. blue spirea, flowering, growth

\begin{abstract}
Plants of blue spirea (Caryopteris incana Mig.) were evaluated as cut flowers in the field and greenhouse. When subjected to several photoperiods but similar cumulative quanta, plants flowered more rapidly at 8 hours than at 12 hours and did not reach the macrobud stage at 16 hours. Stems were longer and their count was significantly higher with a 16-hour than an 8-hour photoperiod. In the field, yield and stem diameter were similar in full sun and in 55\% shade. Stem length, however, significantly increased under shade.
\end{abstract}

Caryopteris incana, a member of Verbenaceae, is a species with potential for field and greenhouse cut flower production. Plants produce lavender-blue cymose flowers in the axils of the opposite leaves. Plants are bo-

Received for publication 3 Oct. 1991. Accepted for publication 17 Aug. 1992. The cost of publishing this paper was defrayed in part by the payment of page charges. Under postal regulations, this paper therefore must be hereby marked $a d$ vertisement solely to indicate this fact.

'Professor.

${ }^{2}$ Postdoctoral Associate. tanically sub-shrubs, and the woody stems die back to the ground when temperatures are below -5C. Caryopteris also includes the hybrid $C$. $\times$ clandenensis (C. incana $\times$ C. mongolica Bunge). Caryopteris incana is less cold hardy than the hybrid (Armitage, 1989), but the flowers more completely surround the stem, resulting in more handsome and more saleable flowering stems. Flowers appear naturally in late summer and fall and continue to appear for $\approx 6$ to 8 weeks. Under favorable conditions, numerous main stems are formed that, in turn, produce lateral stems at each node. Piringer et al. (1963) suggested that flower buds of $C$. xclandenensis initiated regardless of photoperiod but continued to develop only when daily dark periods were $>8 \mathrm{~h}$. Plants subjected to photoperiods $>16$ $\mathrm{h}$ or interrupted nights did not reach anthesis. Flower development of $C$. xclandenensis, from initiation to anthesis, was described by Layzell and Norton (1978). We found no reports, however, on $C$. incana, and the influence of shade on yield and stem quality of that species in the field appears to be unknown.

The objective of this work was to determine photoperiodic guidelines for greenhouse forcing of $C$. incana and its response to shade during outdoor production.

Influence of photoperiod. Seeds received from the Country Garden (Crevitz, Wis.) were sown on 3 Nov. 1989 (Expt. 1) or 5 Mar. 1990 (Expt. 2) under intermittent mist in the Univ. of Georgia greenhouses. The seedlings were potted 2 weeks later in a commercial soilless medium (Fafard 2B, Anderson, S.C.) in standard 560-ml pots. Seedlings were grown for 2 weeks, at which time terminals were pinched to two nodes. Ten plants were randomly placed in plant growth chambers (Model MB-60B, Percival, Mich.) with 8-, 12-, or 16-h photoperiods and kept at $20 \pm 2 \mathrm{C}$ at the top of the plants. The light intensity there, over the course of the study, was 250 to $300 \mu \mathrm{mol} \cdot \mathrm{m}^{-2} \cdot \mathrm{s}^{-1}$ as measured with a LI-COR Quantum Sensor (LI-188B, LI-COR, Lincoln, Neb.) in the 400- to 700-nm range. Cool-white fluores- 


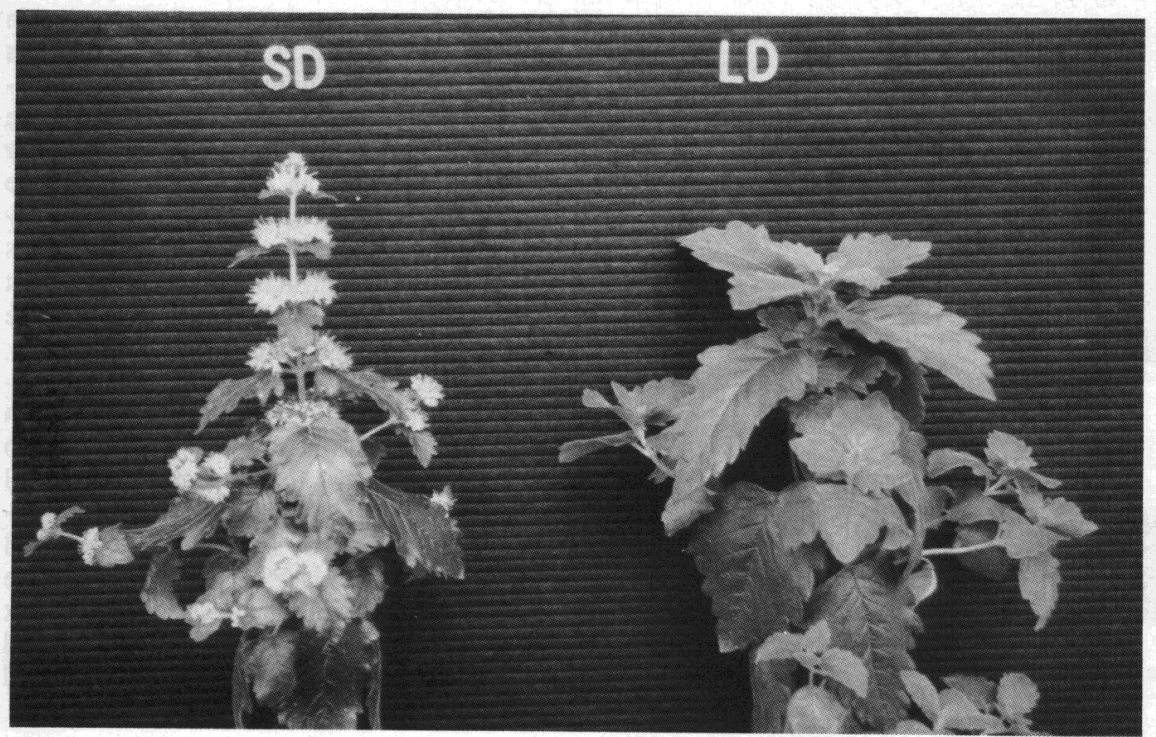

Fig. 1. Effect of photoperiod on flowering of Caryopteris incana. SD: 8-h photoperiod; LD: 16-h photoperiod. Photo taken 70 days after beginning of photoperiodic treatment.

Table 1. Influence of photoperiod on growth and flowering of Caryopteris incana.

\begin{tabular}{|c|c|c|c|c|c|c|c|}
\hline \multirow[b]{2}{*}{$\begin{array}{c}\text { Photoperiod } \\
\text { (h) }\end{array}$} & \multirow{2}{*}{$\begin{array}{l}\text { Time to } \\
\text { macrobud } \\
\text { (days) }^{z}\end{array}$} & \multirow{2}{*}{$\begin{array}{l}\text { Time to } \\
\text { anthesis } \\
\text { (days) }^{z}\end{array}$} & \multicolumn{2}{|c|}{ Plant } & \multicolumn{3}{|c|}{ Stem } \\
\hline & & & $\begin{array}{c}\mathrm{Ht} \\
(\mathrm{cm})\end{array}$ & $\begin{array}{c}\text { Dry wt } \\
\text { (g) }\end{array}$ & Count & $\begin{array}{c}\text { Length } \\
(\mathrm{cm})\end{array}$ & $\begin{array}{l}\text { Diam } \\
(\mathrm{cm})\end{array}$ \\
\hline 8 & $30.3 \mathrm{a}^{\mathrm{y}}$ & $41.5 \mathrm{a}$ & $32.4 \mathrm{c}$ & $3.7 \mathrm{c}$ & $5.0 \mathrm{c}$ & $9.7 \mathrm{~b}$ & $3.7 \mathrm{c}$ \\
\hline 12 & $37.7 \mathrm{~b}$ & $52.5 \mathrm{~b}$ & $41.5 \mathrm{a}$ & $6.7 b$ & $7.4 \mathrm{~b}$ & $16.7 \mathrm{a}$ & $4.6 \mathrm{~b}$ \\
\hline 16 & $\ldots x$ & $\cdots$ & $38.4 \mathrm{~b}$ & $22.1 \mathrm{a}$ & $10.6 \mathrm{a}$ & $17.0 \mathrm{a}$ & $6.3 \mathrm{a}$ \\
\hline
\end{tabular}

'Time from beginning of photoperiod treatment.

${ }^{y}$ Mean differences are based on Tukey's $w$ test $(\sigma=0.05)$.

${ }^{x}$ Event did not occur within 77 days.

cent lamps provided $80 \%$ of the irradiance and $60-\mathrm{W}$ incandescent lamps the remainder. The light intensity over the course of the study varied so that similar irradiance was accumulated each day. Plants received 10.1 to $11.5 \mathrm{~mol} \cdot \mathrm{m}^{-2} \cdot \mathrm{day}^{-1}$, regardless of photoperiod. Transplants were fertilized at each irrigation with 200 ppm N from 15N-9.9P$12.7 \mathrm{~K}$ until water drained from the pots. Tap water only was used every fourth watering to reduce soluble salt accumulation. Time to macrobud and first anthesis were recorded. Plant height, including inflorescence, was measured and plants were harvested at soil level for dry weight determination at time of anthesis. Number, length, and diameter of main stems were also measured. The experiment was terminated 77 days after the beginning of photoperiodic treatments. The experiment was repeated (Expt. 2) in different chambers to reduce chamber effects. Tukey's $w$ test was conducted to determine differences between means.

Influence of shade. Soil type and bed preparation in the cut trial beds at the Univ. of Georgia were similar to those used by Armitage and Laushman (1990). Seeds were sown in early March in the Univ. of Georgia greenhouses and plants were transplanted to the field $\approx 8$ weeks later. A single side dressing of $10 \mathrm{~N}-6.2 \mathrm{P}-8.2 \mathrm{~K}$ was applied 2 weeks after transplanting. Three replications of 40 plants each were planted on $45 \mathrm{~cm}$ centers.
About 55\% shade cloth (Chicopee Manufacturing, Atlanta) was suspended above 20 plants, while the remainder in each replication were grown in full sun. The percentage shade was verified with a LI-COR quantum sensor under sunny and cloudy conditions.

The terminals from each main stem were harvested when about one-half the cymes had reached anthesis. Flowers were harvested between 5 July and 5 Sept. 1988 and 10 July and 1 Sept. 1989. Yield (stems per plant), length of the cut stem, and stem diameter (measured $10 \mathrm{~cm}$ from the base of the cut end) of the main stems were determined for each light treatment. Plants were replanted each year.

Means were compared using analysis of variance $(P=0.05)$.

Influence of photoperiod. Short days are necessary for flower initiation and development of $C$. incana (Table 1). Photoperiods of $\leq 12 \mathrm{~h}$ resulted in flower initiation and normal flower development. This result is not consistent with data of Piringer et al. (1963) who reported that macrobuds occurred during all photoperiods, possibly because they worked with a hybrid (C. $\times$ clandenensis) and did not use controlled environmental rooms. The number of days to anthesis depended on the photoperiod. There was an 11-day difference in onset of anthesis between 8 - and 12-h photoperiods (Table 1); however, no such difference oc- curred for the same photoperiods in the tests of Piringer et al. (1963). No flower buds were visible after 77 days on plants grown under 16-h photoperiods (Fig. 1), suggesting that $C$. incana may be a qualitative shortday plant.

Flowering stems were longer with 12-h than with 8-h days. Stems of plants grown under 16-h photoperiods were more numerous and thicker than those of other plants, regardless of photoperiod, but were taller only than those grown under 8-h days (Table 1). This result would be expected, since stems remained vegetative under the 16-h daylength. Plant height, dry weight, number of stems, stem length, and diameter on plants with a 12-h photoperiod significantly exceeded those of plants that received $8 \mathrm{~h}$. These data suggest that photoperiod significantly influences flower initiation and development of $C$. incana under similar cumulative irradiance.

Influence of shade. Stems per plant (47 to 52 ) and stem diameter $(4.1$ to $4.4 \mathrm{~cm}$ ) were similar for field-grown plants in sun; however, stems were significantly longer under shade (64.5 vs. $58.4 \mathrm{~cm}$ in 1988 and 57.5 vs. $48.5 \mathrm{~cm}$ in 1989 ; both differences $\sigma=$ $0.05)$. Shade has been shown to influence the stem length of numerous cut flower species (Armitage, 1991) and may or may not influence yield, depending on species. In warm, bright climates such as Athens, Ga. (climate zone 7, U.S. Dept. Agriculture, 1990), the addition of shade results in longer, less brittle stems of $C$. incana without loss of yield as expressed as number of stems per plant. Shade, however, may not be necessary in areas of lower summer temperatures such as northwestern North America and coastal California.

This work has shown that flowers of $C$. incana may be forced in the greenhouse by manipulation of photoperiod. Initiation and subsequent flower development may be a qualitative short-day response. Vegetative growth and development, however, are highly responsive to long days and irradiance. Summer field production in the southeastern United States also benefits (longer stems) from the application of shade without a decline in yield or stem diameter.

\section{Literature Cited}

Armitage, A.M. 1989. Herbaceous perennial plants; a treatise of their identification, culture and garden attributes. Varsity Press, Athens, Ga. p. 119-121.

Armitage, A.M. and J.M. Laushman. 1990. Planting date and in-ground time affect cut flowers of Liatris, Polianthes and Iris. HortScience 25:1239-1241.

Layzell, D.B. and R.F. Norton. 1978. Photoperiod and floral bud development in Caryopteris xclandenensis. Can. J. Bot. 56:1844-1851.

Piringer, A.A., R.J. Downs, and H.A. Borthwick. 1963. Photocontrol of growth and flowering of Caryopteris. Amer. J. Bot. 50:86-90.

U.S. Department of Agriculture. 1990. USDA plant hardiness zone map. U.S. Dept. Agr., Misc. Publ. 1475, Washington, D.C. 